The International J ournal of the First Year in Higher Education ISSN: 1838-2959

Volume 6, Issue 1, pp. 187-194

March 2015

\title{
Using the factors that have a positive impact on the retention of low socioeconomic students to prepare accelerated enrolled nurses for the science units of a nursing degree. A Practice Report
}

\author{
Sheila Doggrell and Adam Polkinghorne ${ }^{1}$ \\ Queensland University of Technology, Brisbane, Australia
}

\section{Abstract}

At a campus in a low socioeconomic (SES) area, our University allows enrolled nurses entry into the second year of a Bachelor of Nursing, but attrition is high. Using the factors, described by Yorke and Thomas (2003) to have a positive impact on the attrition of low SES students, we developed strategies to prepare the enrolled nurses for the pharmacology and bioscience units of a nursing degree with the aim of reducing their attrition. As a strategy, the introduction of review lectures of anatomy, physiology and microbiology, was associated with significantly reduced attrition rates. The subsequent introduction of a formative website activity of some basic concepts in bioscience and pharmacology, and a workshop addressing study skills and online resources, were associated with a further reduction in attrition rates of enrolled nursing students in a Bachelor of Nursing.

Please cite this practice report as:

Doggrell, S. \& Polkinghorne, A. (2015). Using the factors that have a positive impact on the retention of low socioeconomic students to prepare accelerated enrolled nurses for the science units of a nursing degree. A Practice Report. The International Journal of the First Year in Higher Education, 6(1), 187-194. doi: 10.5204/intjfyhe.v6i1.277

This practice report has been accepted for publication in Int J FYHE. Please see the Editorial Policies under the 'About' section of the Journal website for further information.

(C) Copyright of practice reports is retained by authors. As an open access journal, articles are free to use, with proper attribution, in educational and other non-commercial settings. ISSN: 1838-2959

\footnotetext{
${ }^{1}$ Dr Adam Polkinghorne was employed at the Queensland University of Technology during this research activity and is now at the University of the Sunshine Coast
} 


\section{Introduction}

Ongoing nursing shortages in many countries have driven the need to train more nurses (e.g. USA; Janiszewski, 2003: Australia; National Review of Nursing Education, 2002; Canada/Australia; Duffield \& O'Brien-Pallas, 2002). Additionally, it is widely acknowledged by health policy makers, providers, clinicians, and social scientists, that a diverse healthcare workforce will improve health disparities in ethnic and other socially disadvantaged groups (reviewed in Gillis, Powell \& Carter, 2010; Bradley, Noonan, Nugent \& Scales 2008). Thus, in many countries, including Australia, Universities face the challenge of producing increasing or similar numbers of students, and diversifying the population of nurses.

One of the primary strategies of increasing participation in nursing education is the introduction of accelerated nursing programs. Students entering these accelerated programs receive academic credit for prior learning in an unrelated field or recognition of an equivalent learning in the form of prior workplace or life experience (National Review of Nurse Education, 2002; Seldomridge \& DiBartolo, 2005).

Our Australian university offers a threeyear undergraduate Bachelor of Nursing degree at a small regional secondary campus in a low SES area. At this campus, all of the accelerated students have completed a non-University course Diploma of Nursing program for enrolled nurses. The accelerated students undertake a unit in pharmacology and an advanced level unit in bioscience, in their first semester, without prior-University teaching of these subjects. Although these accelerated students are having their first year experience of University, they are in the same second year classes as continuing students who have already completed their first year experience. The accelerated students at our low SES campus were having problems adjusting to University, as evidenced by high attrition rates early in the course/program (Figure 1).

We did a search for an intervention model that may be useful for our accelerated students, and identified the model of Yorke and Thomas (2003). These authors identified six Universities in the UK who were performing above the average for completion rates for one of the following: young entrants from working-class backgrounds, young entrants from neighbourhoods with low participation rates, and mature entrants with no familial experience of high education and from low participation neighbourhoods. The low SES backgrounds described by Yorke and Thomas (2003) are probably similar to those of our non-university graduates with diplomas from technical and further education (TAFE) colleges in Australia, as students attending TAFE on average have a lower SES than those attending University (Christie, 2009; Hosken, Land, Goldingay, Barnes, \& Murphy, 2013). Also, the campus where the study was undertaken is in a low SES region of Queensland (Australian Government Department of Education, 2013).

After identification, Yorke and Thomas (2003) questioned the institutions about what they were doing that might account for better completion rates than the benchmark, and concluded that the following factors were having a positive impact on the retention of low SES students and their subsequent success:

1. An institutional climate supportive in various ways of students' development i.e. perceived as "friendly". Thus, students 
were more likely to persist at university, if they developed a relationship with the Institution, which they considered would help them realise their goals.

2. An emphasis on support leading up to, and during, the critically important first year of study. An example of this is that activities in the Orientation [O] week can support students.

3. An emphasis on formative assessment in the early phase of courses, and this assessment should have feedback (Yorke, 2001). This was important as it helped students come to terms with the expectation of the university.

4. Recognition of the importance of the social dimension in learning activities e.g. group learning, group study areas in the library, and/or learning resource centre.

5. Staff development activities that facilitated change in teaching and learning practices in support of the needs of a more diverse student cohort.

Our research was based on factors 1-4 of Yorke and Thomas (2003). In our strategies, factors 1 and 2 were addressed in a skills workshop and review lectures held in $O$-week, and by extra tutorial support. The $O$ week workshop also addressed factor 4 . A formative website activity was developed to address factor 3 .

\section{Methods}

Discussions with the Queensland University of Technology Human Research Ethics Committee indicated that ethical approval was not required for this project, provided students were not identified. Students in the classes examined (Bioscience 3 and Pharmacology) in each year were divided into two cohorts: (i) continuing students - defined as students who already completed one year of studies prior to enrolment in these units; and (ii) accelerated students - defined as enrolled nurses undertaking these second year classes without any prior Nursing undergraduate study. This information was determined for each student using their university academic records.

The strategies were introduced in stages. In 2010, we intervened with review lectures to support the accelerated students, and in 2011, all three parts of the strategies were introduced.

\section{Review lectures}

The review lectures, consisting of material normally given in the first year of the course/program on anatomy, physiology and microbiology, were presented before or at the beginning of semester. The lecture on anatomy and physiology reviewed a number of systems (nervous, endocrine, cardiovascular, respiratory, digestive, renal), and the lecture on microbiology discussed the diversity of microorganisms in relation to human health, the structures of these microorganisms and an introduction to diagnosis of infections.

\section{Establishment of community website and student recruitment}

A community website for the accelerated students in bioscience and pharmacology was established on Blackboard and all of the students in these units were enrolled. The accompanying email stipulated that the community website was designed for accelerated students, but may be a useful refresher for continuing students. In addition to explaining what was available on the website, the class email also invited 
Using the factors that have a positive impact on the retention of low socioeconomic students ...

the accelerated students to the "live" strategies (the $O$ week workshop, and the review lectures). All of the components of the strategies were available on the community website.

\section{1 and 2012 formative website activity}

In the weeks before the start of semester, a formative website activity that considers some basic concepts common to the science units was posted on the community website: Getting Started. This Getting Started website had eChapters, specifically prepared for the accelerated students on: Medical and anatomical terminology; Cell to tissues; Tissues to body; Homeostasis; Physiological feedback mechanisms; Binding sites - the Keys to Pharmacology; Physiological Processes - Links to Pharmacokinetics. These concepts were supported by self-help quizzes, consisting of MCQs posted on the community website, with feedback for each correct and incorrect answer.

\section{1 and 2012 workshop in 0 week}

Accelerated students were invited to a special workshop in 0 week. The workshop started with an introduction to why the strategies were set up, followed by a walk through the community Blackboard site, and the Blackboard site for the individual units. The second part of the workshop discussed library resources available to the students, and was presented by the campus Academic Skills Adviser. The third part of the workshop focused on study skills for active learning as well as specific advice on studying bioscience and pharmacology. Finally, a previous accelerated nursing student discussed their experiences, and how they coped.

\section{Extra tutor for weeks 1-3}

The individual students had extra tutor support for weeks 1-3. This was administered by a tutor using the Blog/Discussion part of Blackboard. Thus, students were able to post questions or problems relating to the lectures, and these were dealt with by the tutor or other students in the group on Blackboard. It was hoped that the Blog/Discussion part of the Blackboard would remain active after the end of support from the tutor, but this did not happen. As a result of this, the extra tutor part of the strategies was not used in 2012.

\section{Data analysis}

The attrition rate was the rate of students' withdrawal from the unit and university. Comparisons of attrition and failure rates of the continuing versus the accelerated students were made by determining the Odds ratio with 95\% confidence levels. Comparison between the percentage marks was made using Students unpaired t-test. For all statistics used, a $p$ value of $\leq .05$ was considered significant.

\section{Results}

\section{Attrition rates}

Up to $50 \%$ of the students enrolled in the bioscience and pharmacology units at the low-SES campus were accelerated students (Table 1), and the attrition rate in 2009 was very high $(\sim 30 \%$, Figure 1$)$. Oddsratio analysis showed that the attrition rates were significantly higher for the accelerated than the continuing students in both the bioscience and pharmacology units: bioscience; odds-ratio $[\mathrm{OR}]=19.6$; $95 \%$ confidence limits [CL], 1.09 to $354, p=$ .04 : pharmacology; $\mathrm{OR}=24.85, \mathrm{CL}, 1.35$ to $456, p=.03$. 
Table 1: Nursing students at low SES campus

\begin{tabular}{||l|l|c|c|c|}
\hline Pharmacology & Student cohort & $\begin{array}{l}\text { Number } \\
\text { (percentage) }\end{array}$ & $\begin{array}{l}\text { Number } \\
\text { that failed }\end{array}$ & $\begin{array}{l}\text { Mark of students } \\
\text { that passed }\end{array}$ \\
\hline $\mathbf{2 0 0 9}$ & Continuing & $28(46 \%)$ & 3 & $62.3 \pm 1.3(25)$ \\
\hline & Accelerated & $33(54 \%)$ & $1(p=.39)$ & $64.6 \pm 2.0(22)$ \\
\hline $\mathbf{2 0 1 0}$ & Continuing & $34(64 \%)$ & 3 & $71.9 \pm 2.0(29)$ \\
\hline & Accelerated & $19(36 \%)$ & $0(p=.37)$ & $69.8 \pm 2.4(18)$ \\
\hline $\mathbf{2 0 1 1}$ & Continuing & $40(64 \%)$ & 2 & $70.7 \pm 1.5(38)$ \\
\hline & Accelerated & $23(36 \%)$ & $2(p=.59)$ & $64.2 \pm 1.9(20)^{*}$ \\
\hline $\mathbf{2 0 1 2}$ & Continued & $45(64 \%)$ & 2 & $63.4 \pm 1.3(41)$ \\
\hline & Accelerated & $25(36 \%)$ & $2(p=.57)$ & $63.3 \pm 1.3(22)$ \\
\hline Bioscience & & & & \\
\hline $\mathbf{2 0 0 9}$ & Continuing & $31(53 \%)$ & 4 & $61.6 \pm 2.6(27)$ \\
\hline & Accelerated & $28(47 \%)$ & $3(p=.81)$ & $61.8 \pm 1.9(16)$ \\
\hline $\mathbf{2 0 1 0}$ & Continuing & $32(62 \%)$ & 3 & $74.5 \pm 2.1(29)$ \\
\hline & Accelerated & $20(38 \%)$ & $0(p=.41)$ & $66.4 \pm 2.7(18) *$ \\
\hline $\mathbf{2 0 1 1}$ & Continuing & $40(66 \%)$ & 2 & $68.5 \pm 1.9(38)$ \\
\hline & Accelerated & $21(34 \%)$ & $1(p=.97)$ & $66.7 \pm 2.2(19)$ \\
\hline $\mathbf{2 0 1 2}$ & Continuing & $50(63 \%)$ & 3 & $67.2 \pm 1.8(46)$ \\
\hline & Accelerated & $29(37 \%)$ & $4(p=.12)$ & $69.5 \pm 2.3(23)$ \\
\hline
\end{tabular}

Odds ratio analysis showed no significant difference in failure numbers between continuing and accelerated students. The $p$ values from this analysis are given in the brackets in the failure column.

Marks are given as mean percentage \pm SEM (number of students)

${ }^{*} p<.05$, unpaired Students t-test, for marks

The introduction of the review lectures presented in 2010, was associated with a drop in the attrition rate of the accelerated student (Figure 1).

Odds-ratio analysis showed that the attrition rates were no longer significantly higher for the accelerated than continuing students in both the bioscience and pharmacology units: bioscience; OR = 10.48; 95\% CL, 0.47 to 232, $p=.14$ : pharmacology; $\mathrm{OR}=8, \mathrm{CL}, 0.83$ to $76.9, p=$ .07. This decrease in student attrition across both units was continued in 2011 when the full strategies was introduced (Figure 1), and there was no significant difference in OR between the continuing and accelerated students: bioscience; OR = 5.9; $95 \%$ CL, 0.23 to $152, p=.28$ : pharmacology; OR $=1.96, \mathrm{CL}, 0.12$ to $33, p$ $=.64$. Similar decreases in accelerated student attrition were also observed in 2012 despite the removal of the online tutorial support (Figure 1). Over the same time period, 2009-2012, the attrition rate was very low for the continuing students (Figure 1). 
Using the factors that have a positive impact on the retention of low socioeconomic students ...
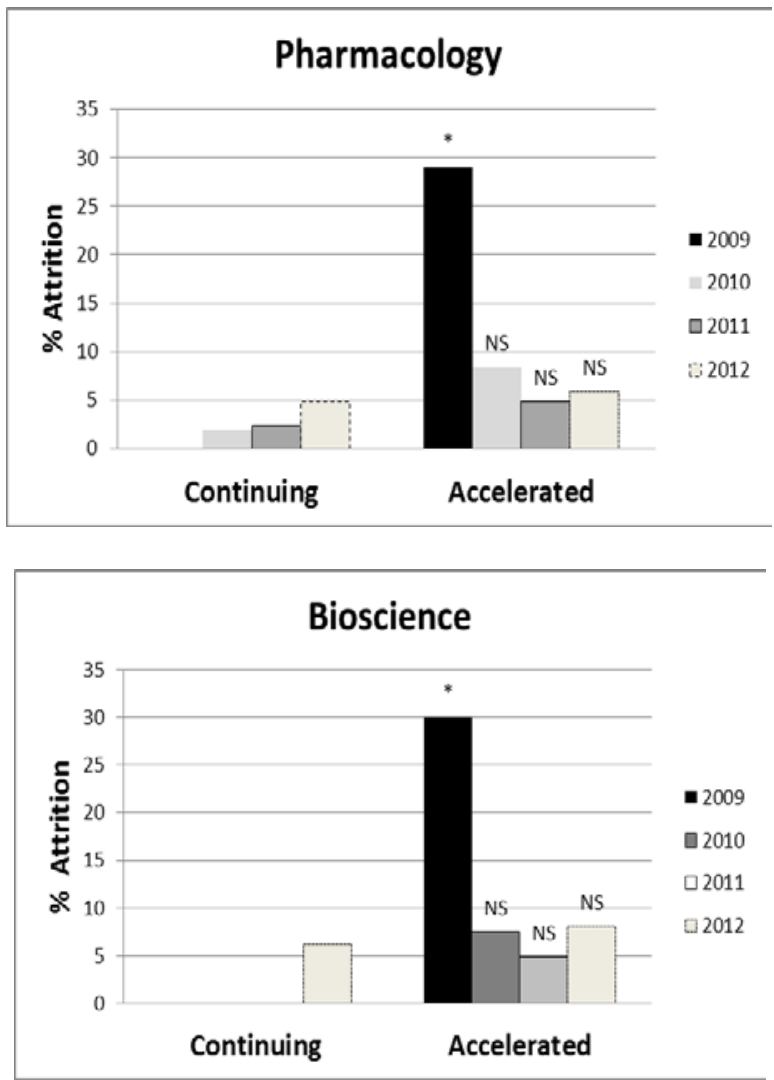

Figure 1: Attrition rates from the pharmacology and bioscience units in 2009-2012.

Percentage attrition is plotted against year for the pharmacology (top) and bioscience (bottom) units.

Odds-ratio analysis: * indicates $p<.05$, NS indicates no significance between accelerated and continuing students for individual years.

Pass and percentage marks of retained students

Only small numbers of continuing and accelerated students who were retained in the units failed the pharmacology and bioscience units in 2009, and these numbers were not significantly different by odds-ratio analysis (Table 1). Despite declining numbers of accelerated students withdrawing in 2010-2012, the number of accelerated students failing these units remained not significantly different to that of the continuing students by odds ratio (Table 1). For the students who passed the units, their percentage marks were not significantly different by Student's unpaired t-test in each year for the accelerated students compared to the continuing students with 2 exemptions; the pharmacology unit in 2011 and bioscience unit in 2010 when the accelerated students had a lower mean mark than the accelerated students (Table 1). 


\section{Discussion}

As discussed in the introduction, Yorke and Thomas (2003) have produced a list of factors that they consider will have a positive impact on the retention of students from low SES backgrounds. However to our knowledge, prior to this study, providing strategies which address these factors to reduce attrition in a low SES community campus has not been tested. In this project, we devised strategies for supporting accelerated students in pharmacology and bioscience units, and these strategies were associated with reduced rates of attrition from these units.

The strategies were probably not the only factors that contributed to the improved retention of accelerated students. In 2009, when there were high attrition rates in Pharmacology/Bioscience at the low SES campus, both study authors were teaching at this campus for the first time, little information was available on the status and background of enrolled accelerated students, and we gave no special consideration to these students. Most of the attrition of accelerated students was early. In 2010-2012, in addition to the strategies described in this manuscript, we were also aware of these students and directly addressed this in the classroom. Presumably, this change of attitude on our part as University teachers may have contributed to the success of our strategies.

It is possible that other changes contributed to the decreased attrition of the accelerated students but we are unaware of any such changes. Thus, to our knowledge, there was no change in admissions policies at the campus during our study or other changes than ours to decrease the attrition of the accelerated students.
Our aim was to develop an approach that can be used in other units/courses/Universities, and we consider we have done this at our low SES campus. Subsequently, we have introduced the strategies into our much larger main campus, where the accelerated students also include international and graduate students, and showed the strategies are associated with increased retention of accelerated students (Doggrell \& Schaffer, 2012).

In our study, there was mainly no significant difference or only a small decrease in performance (percentage marks) between the retained accelerated student academic performance, compared to the continuing students who had already completed one year of study. To our knowledge there is no previous study comparing academic performance between retained accelerated and continuing students.

As stated in the Introduction, Universities around the world are under pressure to produce more nurses. As the strategies we describe in this paper were associated with retaining more accelerated students in Nursing from a low SES area, it will be of interest to determine whether our strategies can be used in other courses with low SES students.

\section{References}

Australian Government Department of Education. (2013). SES scores for census collection districts (CDs) 2009-2013 - based on the SES index for general recurrent grants funding. Retrieved from

https://ssp.education.gov.au/ssp/help/index.ht m\#socioeconomic status (ses)/ses - 20092013/ses scores cd.html

Bradley. D., Noonan, P., Nugent, H., Scales, B. (2008). Review of Australian higher education. Final 
report. Canberra, Australia: Department of Education, Employment and Workplace Relations.

Christie, A. (2009). TAFE Today - A review of the role of TAFE and its closer ties with Universities. Retrieved 10th September, 2014, from http://www.tda.edu.au/resources/Pam Christi e_Speech-Higher_Congress.pdf

Doggrell, S. \& Schaffer, S. (2012). Transferring a successful strategy for supporting accelerated nursing students from a small to a large cohort. Retrieved from http://www.fyhe.com.au/past papers/papers1 2/Papers/7F.pdf

Duffield, C., \& O'Brien-Pallas, L. (2002). The nursing workforce in Canada and Australia: Two sides of the same coin. Australian Health Review, 25, 136-144. doi: 10.1071/AH020136

Gilliss, C., Powell, D., \& Carter, B. (2010). Recruiting and retaining a diverse workforce in nursing: From evidence to best practices to policy. Policy Politics and Nursing Practice, 11, 294-301. doi: $10.1177 / 1527154411398491$

Hosken, N., Land, C., Goldingay, S., Barnes, P., \& Murphy, K. (2013). "I would've been overwhelmed...": The importance of TAFE in supporting success for low SES students in HE. Retrieved from http://fyhe.com.au/past papers/papers13/3B. pdf

Janiszewski, G. (2003). The nursing shortage in the United States of America: An integrative review of the literature. Journal of Advanced Nursing, $43,335-343$.

National Review of Nursing Education. (2002). Our duty of care. Canberra, Australia: Commonwealth of Australia.

Seldomridge, L., \& DiBartolo, M. C. (2005). A profile of accelerated second Bachelor's degree nursing students. Nurse Educator, 30, 65-68. doi: 10.1097/00006223-200503000-00007

Yorke, M., \& Thomas, L. (2003). Improving the retention of students from lower socioeconomic groups. Journal of Higher Education Policy and Management, 25, 63-74. doi: 10.1080/13600800305737

Yorke, M. (2001). Formative assessment and its relevance to retention. Higher Education Research \& Development, 20, 115-126. doi: $10.1080 / 758483462$ 